\title{
Heterotopic Brain Tissue in the Spinal Canal: a Report of an Unusual Case with a Review of the Literature
}

\author{
Marek Mazurek $^{1}$ (D) $\cdot$ Bartłomiej Kulesza $^{1} \cdot$ Bożena Jarosz $^{1} \cdot$ Witold Janusz $^{1} \cdot$ Radosław Rola $^{1}$
}

Received: 14 April 2019 / Accepted: 27 August 2019 / Published online: 9 September 2019

(C) The Author(s) 2019

\begin{abstract}
Heterotopia refers to cells displaced from normal sites, when they are in an aberrant location within their organ of origin. Heterotopic neuroglial tissues are usually located in the nasal region. We present acase of a 69-year-old man with a long history of lumbosacral pain with paresis of the inferior limb. MRI examination detected a cystic tumor located at the L1-L2 level. Histologic examination revealed presence of heterotopic neuroglial tissues, containing synaptophysin, glial cells, and meninges.
\end{abstract}

Keywords Heterotopic brain tissue $\cdot$ Cystic tumor $\cdot$ Lumbar spine canal

\section{Introduction}

Ectopia and heterotopia both refer to cells displaced from normal sites, but ectopic cells occur outside of their organ of origin while heterotopic cells are in an aberrant location within their organ of origin [1]. Heterotopic brain tissue (HBT) is an accumulation of mature brain tissue outside the physiological localization. Pathological masses are usually made of neuronal and glial cells but sometimes they also contain choroid plexus elements [2]. This phenomenon was first described by Reid in 1852 [3]. Despite the long history of observing similar lesions, heterotopic brain tissue is not a frequent occurrence. Fewer than 200 cases have been reported to this day [4]. These anomalies where found in various locations but most commonly they were located in the nasal region [5-7]. To the best of our knowledge, no incidence of heterotopic brain tissue adjacent to the spinal cord in the lumbar region has been reported. The following case is all the more noteworthy because the abnormal tissue led to paresis of the inferior limb.

Marek Mazurek

marekmazurek@hotmail.com

1 Chair and Department of Neurosurgery and Paediatric Neurosurgery, Medical University of Lublin, Lublin, Poland

\section{Case Report}

\section{History and Examination}

The patient was a 69-year-old man who presented with a long history of pain in the lumbosacral region. For about a month and a half, the patient was experiencing increasing back pain radiating to his right leg. The patient had a congenital lumbosacral spinal deformity and skin defect located in the lumbosacral region of the spine. Neurological examination showed decreased mobility and strength in the right inferior limb, 4/5 grade Lovett scale, and with atrophy of all muscle groups within the limb. Additionally, the patient reported hypoesthesia of the buttock and the superior region of the thigh of the right leg, and bowel incontinence.

\section{Imaging Findings}

An MRI study of the lumbar spine demonstrated a cystic lesion, $2.5 \times 0.7 \times 0.9 \mathrm{~cm}$, located at the cauda equina at the L1L2 level. The lesion was well circumscribed, hypointense in comparison with the spinal cord on T1-weighted images with gadolinium enhancement and hyperintense on T2-weighted images (Fig. 1).

\section{Operation and Postoperative Course}

An L1 and L2 laminectomy was performed, and the ligamentum flavum was excised. The dura mater was tense 

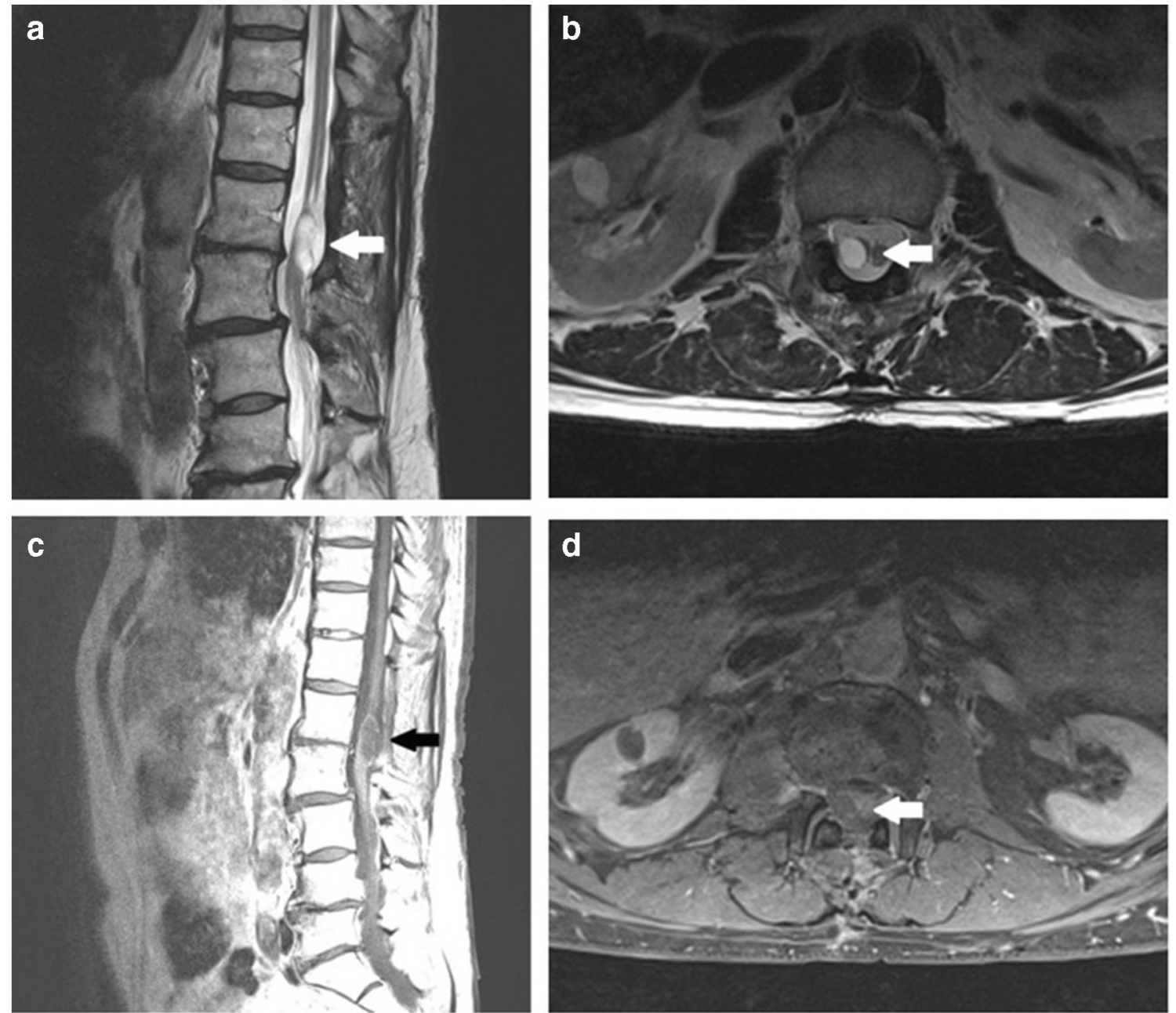

Fig. 1 Preoperative MRI studies demonstrate cystic lesion at the L1-L2 level (arrow) on T2-weighted imaging (a, b) and T1-weighted imaging with Gd enhancement (c, d)

over the bulge of the tumor. The dura was opened with a midline incision. The lesion within the capsule contained thick, whitish fluid of cream-like consistency. Fluid of cystic tumor was aspirated and the capsule was excised. Neither destruction of bone nor any abnormality in the conus medullaris and nerve roots of the cauda equina was observed. The patient awoke with the same overall and neurological status as that before the surgery. He was discharged in good condition after 5 days of postoperative hospitalization. On the month of postoperative follow-up, the patient reported reduction of back pain and hypoesthesia.

\section{Pathological Findings}

Tissue of the cystic lesion obtained at surgery was fixed in $10 \%$ buffered formalin $(\mathrm{pH}=7.4)$ and processed routinely through dehydration with graded alcohol, acetone, and xylene and then embedded in paraffin blocks. Four-micron-thick sections were stained with hematoxylin and eosin (H\&E), and then other histochemical procedures such as Van Gieson and
PAS followed. Sections for immunohistochemistry were mounted on slides coated with organosilane (Dako silanized slides, code no. S3003) to prevent floating of specimen during the immunohistochemical procedure. These sections were stained immunohistochemically using the EnVision ${ }^{\mathrm{TM}}$ Detection System (Dako Real ${ }^{\mathrm{TM}}$ EnVision ${ }^{\mathrm{TM}}$ Detection System, peroxidase/DAB+, rabbit/mouse, code no. K5007) with the following Dako antibodies: S-100 (code no. Z0311; dilution 1:100), GFAP (M0761; 1:100), synaptophysin (M0776; 1:20), EMA (M0613; 1:50), MIB-1 (M7240; 1:150), and CD34 (M7165; 1:50).

The surgical specimens were of gray color, were fragmented, and were of $0.5 \mathrm{~cm}$ in total diameter. Postoperative histopathological examination revealed the presence of the mature synaptophysin-positive neurons in the center of the lesion (Fig. 2c, i) and GFAP-positive glial cells on the periphery (Fig. 2a, h). Both components are also S-100-positive (Fig. 2g). Only a few of the glial cells are immunopositive in reacting with a proliferative marker, MIB-1. On the surface of the lesion, there were meninges with 

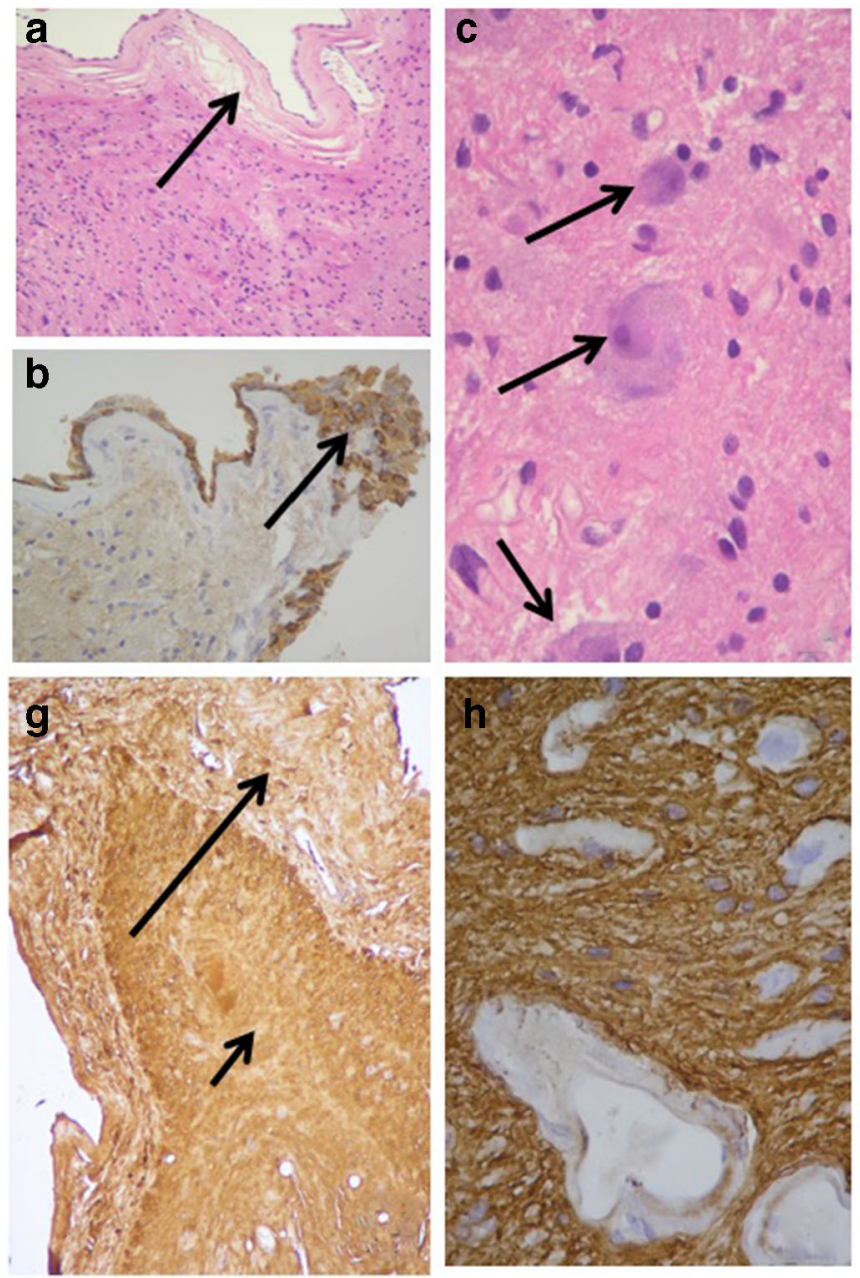

Fig. 2 a Glial cells on the periphery of the lesion and meninges with layers of the meningothelial cells (arrow) (H\&E, $\times 100)$. b EMApositive layer of the meningothelial cells, which focally formed clusters of cells (arrow). c Mature neurons in the center of the sample (arrows) $(\mathrm{H} \& \mathrm{E}, \times 400)$. d Small amyloid body $(\mathrm{H} \& \mathrm{E}, \times 600)$. e PAS-positive amyloid bodies (PAS, $\times 600$ ). f Small cyst lined by meningothelial cells (arrow) within the largest piece of the specimen (H\&E, $\times 100)$. g S-100

layers of meningothelial cells (Fig. 2a), which focally formed clusters of cells (Fig. 2b). Besides, there were small and dispersed amyloid bodies (Fig. 2d, e). Small cysts lined by meningothelial cells were visible within the largest piece of the specimen (Fig. 2f).

\section{Discussion}

The pathogenesis of this kind of tissue is unclear. There are many theories which try to explain the origin of heterotopic brain tissue. One of them suggests that HBT may be due to separation of extracranial embryonic neuronal tissue through changes during cranial closure. It has been reported that $25 \%$ of nasal HBT lesions have a fibrous extradural connection to
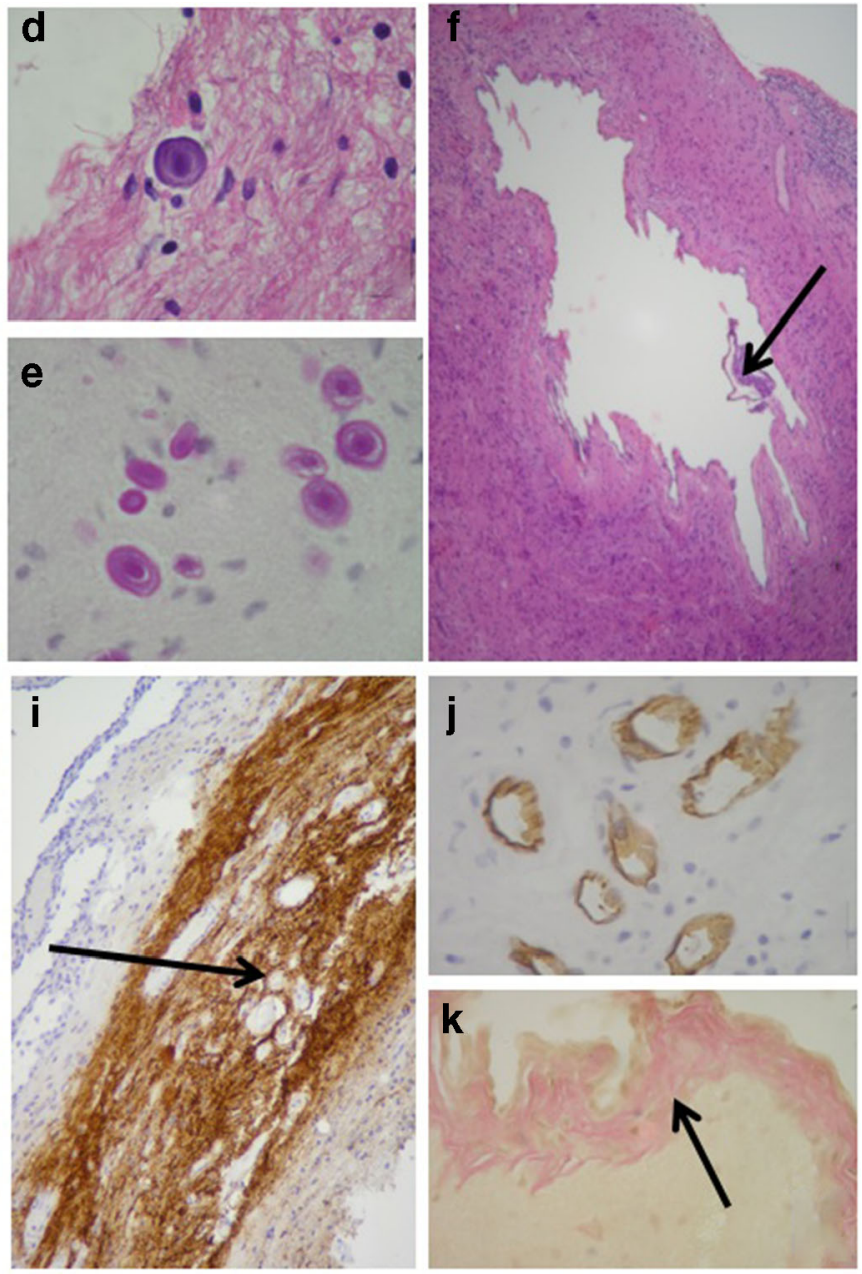

positivity of the peripheral glial component of the lesion (long arrow) and strong positivity of the central neuronal component (short arrow) (S-100, $\times 100$ ). $\mathbf{h}$ GFAP positivity of the peripheral glial component of the lesion; the wall of the vessels is negative (GFAP, $\times 400)$. i Synaptophysin positivity of the central neuronal component (arrow) (Syn, $\times 100$ ). j CD34positive endothelial cells of the vessels $(\mathrm{CD} 34, \times 400)$. $\mathbf{k}$ Fibrous tissue of the meninges (arrow) (Van Gieson, $\times 400$ )

the central nervous system, which seems to confirm this theory [8]. Another hypothesis suggests that HBT was derived from extracranial separation of embryonic neuronal tissue, which was independent of cranial closure. An alternative theory assumes that heterotopic lesions may result from isolated pluripotent neuroectodermal cells which then gradually transform into mature tissue [2, 4]. There are also some studies which suggest that genetic factors may contribute to neuronal overmigration and neuronal ectopia [9]. On the other hand, no familial tendency and gender preference connections were found in relation to the occurrence of HBT [4].

The case we present is unusual in many terms. In the observations carried out so far, the most common location of heterotopic brain tissue was the nasal region [7]. In $60 \%$ of these cases, the lesions occurred extranasally, usually on the 
midline over the bridge of the nose. Thirty percent of them were located intranasally along the lateral wall of the nose. Location in $10 \%$ was combined [7]. Non-nasal location was less frequent; however, ectopic brain tissue has been reported to occur in the pharynx, lung, orbits, palate, tongue, cheek, lips, and neck $[5,6]$. As previously mentioned, according to our knowledge, this is the first case of heterotopic brain tissue adjacent to the spinal cord in the lumbar region that has been reported.

Majority of the times, heterotopic neuronal tissues were found in early infancy or childhood. However, there have been several cases of lesions in older age, as in our case [10, 11]. This situation may result from the fact that HBT lesions are usually asymptomatic and they are often discovered incidentally for unrelated reason by imaging examination [2]. In symptomatic cases, the manifestations are mainly due to the mass effect. Lesions in the nasal area quite often cause respiratory difficulties due to compression of the airway [4]. In our case, the presence of heterotopic brain tissue adjacent to the spinal cord led to compression of nerve fibers and paresis of the inferior limb. Destruction of surrounding tissues in the case of HBT is caused by the mass effect. There are no reports of malignant degeneration in heterotopic brain tissue [4].

Due to the asymptomatic nature of the changes, treatment is often unnecessary. Surgical procedures are indicated in symptomatic cases in which it may bring relief of symptoms [12]. In the case of our patient, the treatment caused a reduction of back pain and hypoesthesia. The relapse rate after surgical treatment of the heterotopic brain tissue is low. It is claimed that it ranges from 4 to $10 \%$ [13].

\section{Conclusions}

In summary, heterotopic neuroglial tissue in the lumbar spinal canal is a very uncommon lesion, and preoperative diagnosis of this lesion is difficult. Imaging studies and histologic examination are the necessary investigations for diagnosis. Surgical treatment is the best choice for a symptomatic patient with pathological lesion in the spinal canal. The outcome is similar to other benign lesions in this location.

\section{Compliance with Ethical Standards}

Conflict of Interest The authors declare that they have no conflict of interest.
Open Access This article is distributed under the terms of the Creative Commons Attribution 4.0 International License (http:// creativecommons.org/licenses/by/4.0/), which permits unrestricted use, distribution, and reproduction in any medium, provided you give appropriate credit to the original author(s) and the source, provide a link to the Creative Commons license, and indicate if changes were made.

\section{References}

1. Sarnat HB (1995) Ectopic or heterotopic? An appeal for semantic precision in describing developmental disorders of the nervous system. Pediatr Neurol 13:178-179

2. De Donato G, De Stefano A, Dispenza F, Kulamarva G, Piccirillo E (2007) Chronic otitis caused by heterotopic brain tissue in pterygopalatine fossa. Int J Pediatr Otorhinolaryngol 2(4):235-237

3. Behar PM, Muller S, Gerber ME, Todd NM (2001) Heterotopic neuroglial tissue causing airway obstruction in the new born. Arch Otolaryngol Head Neck Surg 127:997-1002

4. Cheng-Yi C, Kun-Eng L, Yuan-Yu H, Yueh-Hua T, Hsu-Chao C, Hsiu-Wen K (2006) Cystic heterotopic brain tissue presenting as a unilateral neck mass-a case report. TZU CHI Med J 18(3):217-219

5. Buccoliero AM, Caldarella A, Noccioli B, Fiorini P, Taddei A, Taddei GL (2002) Brain heterotopia in pharyngeal region. A morphological and immunohistochemical study. Pathol Res Pract 198(1):59-63

6. Conner AK, Fung KM, Peterson JE, Glenn CA, Martin MD (2016) Ectopic ganglion in cauda equina: case report. J Neurosurg Spine $12: 1-4$

7. Ducic Y (1999) Nasal gliomas. J Otolaryngol 28:285-287

8. Cohen AH, Abt AB (1970) An unusual case of neonatal respiratory obstruction: heterotopic pharyngeal brain tissue. J Pediatr 76:119122

9. Li S, Jin Z, Koirala S, Bu L, Xu L, Hynes RO, Walsh CA, Corfas G, Piao X (2008) GPR56 regulates pial basement membrane integrity and cortical lamination. J Neurosci 28:5817-5826

10. Hendrickson M, Faye-Petersen O, Johnson DG (1990) Cystic and solid heterotopic brain in the face and neck: a review and report of an unusual case. J Pediatr Surg 25:766-768

11. Penner CR, Thompson LRD (2003) Nasal glial heterotopia: a clinicopathologic and immuno phenotypic analysis of 10 cases with a review of the literature. Ann Diagn Pathol 7(6):354-359

12. Kalmann JE, Loevner LA, Yousem DM, Chalian AA, Lanza DC, Jin L, Hayden RE (1997) Heterotopic brain in pterygopalatine fossa. AJNR Am J Neuroradiol 18:176-179

13. Giannas JE, Bayat A, Davenport PJ (2005) Heterotopic nasopharyngeal brain tissue associated with cleft palate. Br J Plast Surg 58(6):862-864

Publisher's Note Springer Nature remains neutral with regard to jurisdictional claims in published maps and institutional affiliations. 